\title{
Thermophilic two-phase anaerobic digestion using an innovative fixed-bed reactor for enhanced organic matter removal and bioenergy recovery from sugarcane vinasse
}

\author{
Lucas Tadeu Fuess ${ }^{a, *}$, Luma Sayuri Mazine Kiyuna ${ }^{a}$, Antônio Djalma Nunes Ferraz Júnior ${ }^{b}$, \\ Gabriela Felix Persinoti ${ }^{\mathrm{b}}$, Fabio Marcio Squina ${ }^{\mathrm{b}}$, Marcelo Loureiro Garcia ${ }^{\mathrm{c}}$, Marcelo Zaiat ${ }^{\mathrm{a}}$ \\ ${ }^{a}$ Biological Processes Laboratory (LPB), São Carlos School of Engineering (EESC), University of São Paulo (USP), Av. João Dagnone, 1100, Santa Angelina, São Carlos, São Paulo \\ 13563-120, Brazil \\ ${ }^{\mathrm{b}}$ Laboratório Nacional de Ciência e Tecnologia do Bioetanol (CTBE), Centro Nacional de Pesquisa em Energia e Materiais (CNPEM), Rua Giuseppe Máximo Scolfaro, 10000, Polo II \\ de Alta Tecnologia, P.O. Box 6170, Campinas, São Paulo 13083-970, Brazil \\ ${ }^{\mathrm{c}}$ Institute of Geosciences and Exact Sciences, UNESP - Univ Estadual Paulista, Av. 24-A, 1515, Bela Vista, Rio Claro, São Paulo 13506-900, Brazil
}

\section{H I G H L I G H T S} reactor was applied to sugarcane vinasse.

- Stable operation was observed for OLRs as high as $30 \mathrm{~kg} \mathrm{COD} \mathrm{m} \mathrm{may}^{-1}$.

- Propionate buildup did not impact the stability of the structured-bed reactor.

- Enhanced bioenergy recovery was estimated from biodigestion with phase separation.

- Energy extraction was over $20 \%$ higher compared to single-phase systems.
- An innovative fixed-film anaerobic
G R A P H I C A L A B S T R A C T

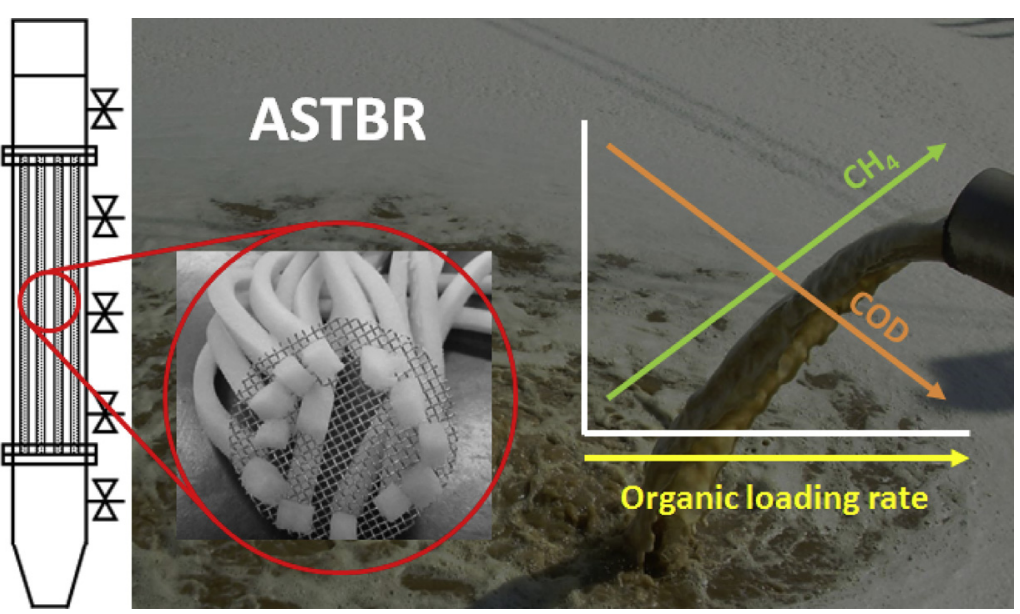

\section{A B S T R A C T}

This study considered the application of anaerobic digestion (AD) with phase separation combined with the use of an anaerobic structured-bed reactor (ASTBR) as the methanogenic phase for the treatment of sugarcane vinasse, a high-strength wastewater resulting from ethanol production. Two combined thermophilic acidogenic-methanogenic systems formed by one single acidogenic reactor followed by two methanogenic reactors operated in parallel were compared, namely, a conventional UASB reactor and an upflow ASTBR reactor. Increasing organic loading rate (OLR) conditions (15-30 $\mathrm{kg} \mathrm{COD} \mathrm{m}^{-3} \mathrm{~d}^{-1}$ ) were applied to the methanogenic reactors. The results highlighted the feasibility of applying the ASTBR to vinasse, indicating a global COD removal higher than $80 \%$. The ASTBR exhibited a stable long-term operation (240 days), even for OLR values as high as $30 \mathrm{~kg} \mathrm{COD} \mathrm{m}^{-3} \mathrm{~d}^{-1}$. The application of similar conditions to the UASB reactor indicated severe performance losses, leading to the accumulation of acids for every increase in the OLR. An energetic potential of $181.5 \mathrm{MJ}$ for each cubic meter of vinasse was estimated from both hydrogen and methane. The provision of bicarbonate alkalinity proved to be a key factor in

\section{Keywords:}

Sugarcane vinasse

Structured-bed reactor

Innovative system

Long-term stable operation

Biohydrogen

Bioenergy recovery
* Corresponding author.

E-mail addresses: ltfuess@sc.usp.br (L.T. Fuess), luma.kiyuna@usp.br (L.S.M. Kiyuna), djalmaferraz@gmail.com (A.D.N. Ferraz Júnior), gabriela.persinoti@bioetanol.org.br (G.F. Persinoti), fabio.squina@bioetanol.org.br (F.M. Squina), mlgarcia@rc.unesp.br (M.L. Garcia), zaiat@sc.usp.br (M. Zaiat). 
obtaining stable performance, offsetting the limitations of relatively low hydraulic retention times $(<24 \mathrm{~h})$.

(c) 2016 Elsevier Ltd. All rights reserved.

\section{Introduction}

The application of anaerobic processes to the treatment of highstrength wastewaters (HSWs) has shown remarkable progress in recent decades based on the development and improvement of high-rate systems [1,2]. In brief, the decoupling between the hydraulic retention time (HRT) and solids retention time (SRT) allowed for the application of high organic loadings at a relatively low HRTs considering the establishment of high cell densities within the reactors $[2,3]$. However, despite this development, further investigations are still required to overcome the limitations of the available reactor configurations and process designs to increase both organic matter conversion and energy recovery through methane. Moreover, considering the depletion scenarios extensively associated with the availability of natural resources, anaerobic digestion (AD) must not be characterized uniquely as a process to reduce the polluting load of residues and mitigate environmental impacts. In fact, recent studies highlight the role of AD as a core resource-recovering process to enable the use of residues as raw materials for the production of value-added products and bioenergy, i.e., the concept of biorefinery [4,5].

Phase separation comprises an attractive approach to overcome limitations in the application of AD to HSW and thus enhance the direct and/or indirect energy extraction from residues, as a range of important benefits may be observed. Under appropriate conditions, the hydrolysis step tends to be enhanced in the acidogenic phase of the two-phase AD systems [6]. Marked improvements in the biodegradability of wastewaters, as well as higher energy yields, should also be observed in combined acidogenicmethanogenic processes as a direct consequence of a more stable methanogenesis [7-9]. Such conditions arise from the ready availability of acetate to methanogens [10], either directly by the fraction of acetic acid from acidogenesis or indirectly by the prompt conversion of propionic and butyric acids to acetate by the acetogenic bacteria. The production of biohydrogen within the acidogenic phase may also play an important role in enhancing the energy yield from AD in combined systems [9], although most of the energetic potential derives from a more efficient conversion of the organic matter into methane [11].

Among the different types of wastewaters potentially suited to $A D$, particular attention should be given to sugarcane vinasse, the primary wastewater from ethanol production [12]. Recent studies have estimated an appreciable energetic potential for sugarcane vinasse [13-15], which may enhance the net energy balance of ethanol plants through electricity generation from biogas. However, further improvements in the application of AD are still required to better exploit sugarcane vinasse as a raw material for the production of bioenergy in full-scale plants, aiming at the application of high organic loading rates (OLRs) at relatively low HRTs. Such enhancements could be achieved by employing combined acidogenic-methanogenic AD systems based on the intrinsic compositional characteristics of vinasse. The complex organic matter typically found in vinasse may be hydrolyzed in the first phase under appropriate conditions, whereas the remaining fractions of carbohydrates (4.1-5.6 $\left.\mathrm{g} \mathrm{L}^{-1}[16,17]\right)$ may potentially be converted into biohydrogen and volatile fatty acids (VFAs) as a result of acidogenesis. In addition, the high temperatures at which vinasse is generated $\left(90-100^{\circ} \mathrm{C}\right)$ enable the use of thermophilic processes in the treatment plants, which may be attractive for combined anaerobic systems. The production of biohydrogen is energetically more favorable at higher temperatures [18], increasing the amount of energy extracted from vinasse. In addition, studies typically indicate the application of higher organic loadings to thermophilic anaerobic reactors compared to mesophilic systems as a direct consequence of higher reaction rates, which also enhance the hydrolysis of complex organic compounds [18].

Focusing on the methanogenic phase, studies on the application of $A D$ to sugarcane vinasse are frequently based on upflow sludge blanket (UASB) reactors [11,19-22]. However, biomass washout may arise due to the increasing upflow velocities in such systems [2], which may limit the application of high OLR conditions in compact units, as desired for sugarcane vinasse. Biomass washout may also be enhanced by high concentrations of suspended solids, which inhibit the granulation process in the UASB reactors by limiting the contact between the micro-organisms [2,23,24]. Moreover, most studies on the application of $A D$ to sugarcane vinasse in the Brazilian sucro-alcohol industry were performed in the early 1980-90s [19-21], with only a few recent experimental [11,25-26] and theoretical and/or simulation-based [13-15] studies, still considering the sludge blanket systems as the reactor in single-phase schemes. In terms of experimental results, Barros et al. [26] reported COD removal efficiencies as high as $80 \%$ for UASB reactors applied to diluted vinasse; however, relatively low OLRs (up to $11.5 \mathrm{kgCOD} \mathrm{m}^{-3} \mathrm{~d}^{-1}$ ) and high HRTs (2.8-1.8 days) were used. In the case presented by Siqueira et al. [25], although OLRs as high as $26.2 \mathrm{kgCOD} \mathrm{m}^{-3} \mathrm{~d}^{-1}$ were applied to a fluidized-bed also treating sugarcane vinasse, the influent was also diluted prior to feeding the system, and COD removal decreased to only $51 \%$ as the OLR was increased. Ferraz Jr. et al. [11] also reported the application of high OLRs (up to $25 \mathrm{kgCOD} \mathrm{m}^{-3} \mathrm{~d}^{-1}$ ) in a sludge-blanket reactor fed with raw vinasse; however, COD removal levels were still insufficient (60.7\%). Those authors also studied the application of a two-phase $\mathrm{AD}$ system to vinasse, which also indicated COD removal levels of less than $70 \%$. With respect to the theoretical results, Moraes et al. [14] presented a detailed report addressing technical, economic and environmental aspects related to the implementation of $\mathrm{AD}$ to sugarcane biorefineries. However, the calculations were based on data from a single-phase system previously described by Souza et al. [21], i.e., a gap of over 20 years. In the cases of Salomon et al. [13] and Fuess and Garcia [15], details on the reactor type were not presented.

In addition to phase separation, the use of fixed-bed systems, particularly the anaerobic structured-bed reactor (ASTBR), could be more effective for coupling enhanced performances with the application of high organic loadings in AD systems applied to sugarcane vinasse. The ASTBR is a novel fixed-film system recently applied to the organic matter removal and sulfate reduction from low-strength wastewaters [27]. This technology combines the advantages of immobilized cell growth, such as lower sensitivity to environmental variations (i.e., $\mathrm{pH}$, temperature and OLR) and higher substrate conversion rates [1], with higher bed porosity, preventing the accumulation of extracellular polymeric compounds and suspended solids [27]. The higher void index allows for designing more compact units than conventional packed-bed systems. Moreover, the ASTBR requires lower energy input than second generation sludge blanket reactors (i.e., expanded and 
fluidized-bed systems), as the biomass is attached throughout the entire length of the reactor, and thus sludge expansion is eliminated. In fact, although expanded and the fluidized-bed systems allow the achievement of extreme OLRs, such as $20-40 \mathrm{~kg}$ COD $\mathrm{m}^{-3} \mathrm{~d}^{-1}$ at full scale [2], high energy levels are required to expand the granular sludge or the support material in such cases. Particularly for fluidized-bed systems, up to $13 \%$ of the biogas energy may be required for pumping the liquid phase [28], which may hinder the recovery of bioenergy.

In this context, this paper aimed to assess the applicability of both AD with phase separation and an ASTBR as the methanogenic phase for sugarcane vinasse treatment. Two combined thermophilic acidogenic-methanogenic systems, formed by one single acidogenic reactor followed by two methanogenic reactors operated in parallel, namely, a conventional UASB reactor and an upflow ASTBR, were analyzed. The performance of the systems was compared in terms of operational stability, organic matter removal and energy recovery, with an emphasis on the methanogenic phase. With respect to the energy recovery, an energy balance including the contribution of biohydrogen production on the energetic potential of vinasse was performed to highlight the potential of phase separation to enhance bioenergy recovery from vinasse. Despite the potential suitability of the ASTBR for the treatment of HSWs, no reports have examined the application of this reactor configuration to sugarcane vinasse. In fact, the present study represents the first attempt to apply an ASTBR to the treatment of sugarcane vinasse under high-rate conditions. Moreover, despite the proven suitability of applying $\mathrm{AD}$ to the treatment of sugarcane vinasse $[11,19-21,25-26]$, complementary investigations are still required to overcome the limitations of the available reactor configurations and process designs to increase both organic matter conversion and energy recovery through methane by focusing on further full-scale applications. The results obtained herein fill this technological gap and highlight the robustness of the ASTBR for the application of OLRs similar to those usually applied to second generation sludge blanket systems.

\section{Material and methods}

\subsection{Vinasse characterization}

Sugarcane vinasse samples were collected from a full-scale ethanol and sugar plant located in Pradópolis, SP, Brazil. The main physicochemical characteristics of the raw vinasse, i.e., the vinasse that was applied to the acidogenic reactor, were as follows: total chemical oxygen demand (TCOD) $-28.3 \pm 4.6 \mathrm{~g} \mathrm{~L}^{-1}$; soluble chemical oxygen demand (SCOD) - $22.9 \pm 4.0 \mathrm{~g} \mathrm{~L}^{-1}$; biochemical oxygen demand (BOD) - $14.6 \pm 3.5 \mathrm{~g} \mathrm{~L}^{-1}$; BOD/TCOD ratio $=0.51 \pm 0.07$; total phosphorus - $113 \pm 105 \mathrm{mg} \mathrm{L}^{-1}$; total Kjeldahl nitrogen $862 \pm 219 \mathrm{mg} \mathrm{L}^{-1}$; total volatile solids (TVS) - 20,775 \pm 3416 $\mathrm{mg} \mathrm{L}^{-1}$; volatile suspended solids (VSS) - $1002 \pm 243 \mathrm{mg} \mathrm{L}^{-1}$; sulfate $\left(\mathrm{SO}_{4}^{2-}\right)-1700 \pm 430 \mathrm{mg} \mathrm{L}^{-1}$ and $\mathrm{pH}-4.5 \pm 0.1$. Vinasse was filtered with $3 \mu \mathrm{m}$ filter paper (Nalgon, density of $80 \mathrm{~g} \mathrm{~m}^{-2}$ ) prior to feeding the reactor to prevent operating problems within the bench-scale apparatus, such as the accumulation of solids in the pumps and packed-bed of the acidogenic reactor. The values of TCOD, TVS and VSS correspond to the concentrations of organic matter and solids in the filtered samples. The filtration step could be eliminated in full-scale systems due to the higher capacity of the pumping systems.

\subsection{Acidogenic phase: Reactor and operating conditions}

The acidogenic phase was composed of a bench-scale $(2.3 \mathrm{~L})$ packed-bed reactor (APBR). The reactor design, experimental appa- ratus, inoculation, operating conditions and results of the longterm operation were previously reported in detail by Fuess et al. [17]. In brief, the APBR was filled with low-density polyethylene (LDPE) pieces and operated for 240 days under thermophilic temperature conditions $\left(55^{\circ} \mathrm{C}\right)$, with a continuous OLR of $84.2 \mathrm{~kg} \mathrm{COD} \mathrm{m}^{-3} \mathrm{~d}^{-1}$ (HRT of $7.5 \mathrm{~h}$ ). The $\mathrm{pH}$ of the vinasse was adjusted between 5.5 and 7.5 prior to feeding the acidogenic reactor using a solution of sodium hydroxide $(\mathrm{NaOH})$ at $50 \% \mathrm{~m} / \mathrm{v}$.

\subsection{Methanogenic phase: Reactors and operating conditions}

Methanogenic reactors were also operated at the bench-scale $2.5 \mathrm{~L}$ (ASTBR) and 3.5 L (UASB) - and inoculated using thermophilic sludge (TVS $=134 \mathrm{~g} \mathrm{~L}^{-1}$; total solids $-\mathrm{TS}=245 \mathrm{~g} \mathrm{~L}^{-1}$ ) from a fullscale UASB applied to the treatment of sugarcane vinasse. Fig. 1 shows the basic layout of the experimental apparatus and various construction characteristics of the ASTBR. The UASB was inoculated by filling approximately $40 \%$ of the useful volume of the reactor with the thermophilic sludge, after which the operation of the reactor was initiated. In the case of the ASTBR, the sludge was initially diluted with tap water $(1: 1)$, ground and applied to polyurethane (PU) foam strips for $2 \mathrm{~h}$ according to the protocol described by Zaiat et al. [29]. The excess ground sludge was then drained from the reactor, and the fermented vinasse was applied. The porosity of the ASTBR was $96 \%$. Alkalinity was provided to the fermented vinasse by adding sodium bicarbonate $\left(\mathrm{NaHCO}_{3}\right)$, leading to an average $\mathrm{pH}$ of approximately 7.0.

The operation of the reactors was initially divided into three phases based on the application of increasing OLRs $(15,20$ and $\left.25 \mathrm{~kg} \mathrm{COD} \mathrm{m}^{-3} \mathrm{~d}^{-1}\right)$. An additional OLR increase (30 $\mathrm{kg} \mathrm{COD} \mathrm{m}^{-3}$. $\mathrm{d}^{-1}$ ) was tested in the ASTBR after the third phase to define the operating limit of the reactor. The increasing OLR promoted reductions in the HRT applied to the reactors, which decreased from approximately $37 \mathrm{~h}\left(15 \mathrm{~kg} \mathrm{COD} \mathrm{m}^{-3} \mathrm{~d}^{-1}\right)$ to $18-20 \mathrm{~h} \mathrm{(30} \mathrm{kg} \mathrm{COD}$ $\mathrm{m}^{-3} \mathrm{~d}^{-1}$ ). Peristaltic pumps (Model Minipuls Evolution, Gilson, Inc., Middleton, WI, USA) were used in the feeding of both reactors (Fig. 1). Finally, the UASB and ASTBR were operated for 210 and 240 days, respectively, slightly longer than the average duration of the sugarcane season in Brazil.

\subsection{Performance evaluation: Analytical methods}

The performance of the acidogenic phase, i.e., the conversion of carbohydrates, production of biohydrogen and fermentation intermediates obtained, has also been presented in detail by Fuess et al. [17]. Therefore, the following section focuses on the methods applied to the methanogenic phase. The monitoring of the methanogenic reactors was based on the following parameters: $\mathrm{pH}$, TCOD, SCOD, VSS, volatile fatty acids (VFAs) and solvent levels, partial alkalinity (PA, i.e., the alkalinity resulting from bicarbonate) and intermediate alkalinity (IA, i.e., the alkalinity resulting from dissociated VFAs). The $\mathrm{pH}, \mathrm{TCOD}, \mathrm{SCOD}$ and VSS values were obtained according to the Standard Methods for Examination of Water and Wastewater [30]. VFAs (acetic, propionic, butyric, isobutyric, valeric, isovaleric and caproic acids) and solvents (methanol, ethanol and $n$-butanol) were analyzed by gas chromatography with flame ionization detection (GC/FID) according to the protocol described by Adorno et al. [31]. Prior to SCOD and VFA analyses, the samples were filtered with $0.45 \mu \mathrm{m}$ membranes. PA and IA were monitored according to Ripley et al. [32]. In addition, total carbohydrates were analyzed by the phenol-sulfuric method [33] such that the values obtained were used in the calculation of the mass balances for the reactors.

The biogas flow rate was measured using gas meters (model MGC-1 V30, Dr.-Ing. Ritter Apparatebau GMBH \& Co. KG, Bochum, Germany) coupled to the headspace of the reactors (Fig. 1a). Biogas 

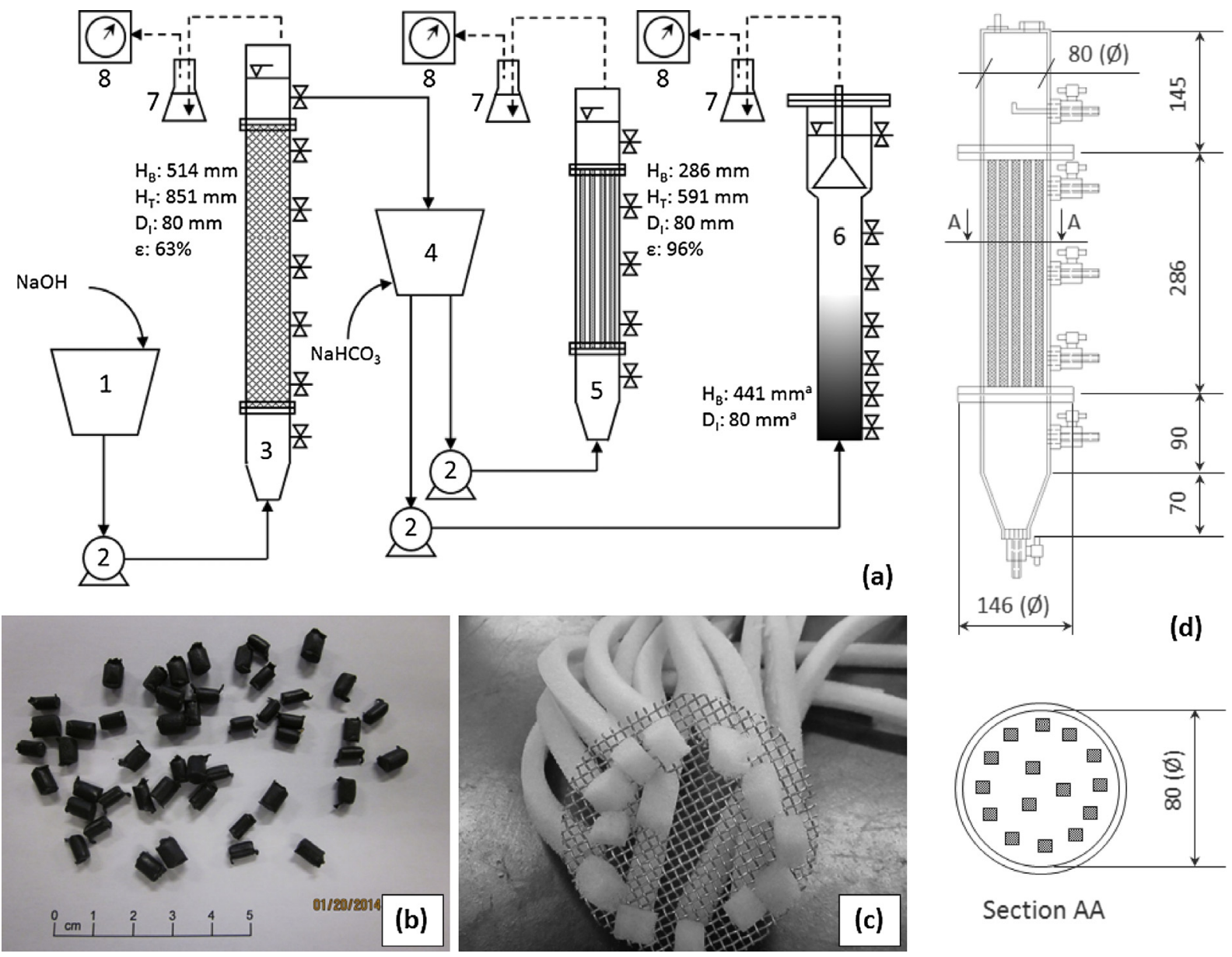

Section AA

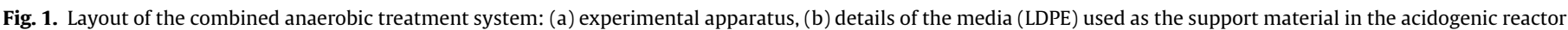

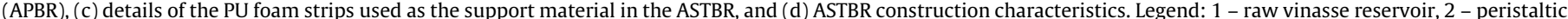

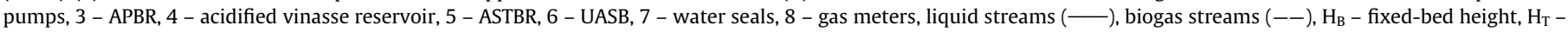

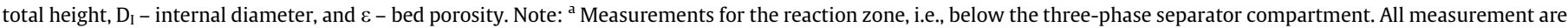
in millimeters.

composition (hydrogen, carbon dioxide and methane) was determined with a gas chromatograph (model GC-2010, Shimadzu Scientific Instruments, Columbia, MD, USA), equipped with a thermal conductivity detector (GC/TCD) with argon as the carrier gas and a Carboxen 1010 PLOT column (30 m, $0.53 \mathrm{~mm}$ ) [34].

The response variables used to assess the performance of the methanogenic reactors included the removal of TCOD $\left(E_{\mathrm{TCOD}}\right.$, in $\%$ ) and SCOD (ER $\mathrm{SCOD}_{\mathrm{S}}$, in \%), biogas flow rate (BFR, in $\left.\mathrm{mL} \mathrm{d}^{-1}\right)$, volumetric methane production rate (VMPR, in $\mathrm{mLCH}_{4} \mathrm{~L}^{-1} \mathrm{~d}^{-1}$ ), methane yield (MY, in $\mathrm{mLCH}_{4} \mathrm{~g}^{-1} \mathrm{COD}_{\text {removed }}$ ) and intermediate/partial alkalinity (IA/PA) ratio.

\subsection{Energetic potential estimation}

The energetic potential (EP, in $\mathrm{MJ} \mathrm{m}_{\text {vinasse }}^{-3}$ ) of the biogas resulting from the anaerobic digestion of vinasse was calculated according to Eqs. (1) and (2), as previously reported by Fuess and Garcia [15]. Eq. (1) addresses the energy generation from methane, whereas hydrogen is used as the energy carrier in Eq. (2).

$$
\begin{aligned}
& E P\left(\mathrm{CH}_{4}\right)=C O D \cdot E R_{\mathrm{COD}} \cdot M Y \cdot L H V_{\mathrm{CH} 4} \\
& E P\left(\mathrm{H}_{2}\right)=C H \cdot E C_{C H} \cdot H Y \cdot L H V_{\mathrm{H} 2}
\end{aligned}
$$

In Eq. (1), the terms COD, ER $\mathrm{COD}_{\mathrm{C}}$, MY and $\mathrm{LHV}_{\mathrm{CH} 4}$ are the COD of vinasse $\left(\mathrm{kg} \mathrm{m}^{-3}\right)$, the removal of $\operatorname{COD}(\%)$, the methane yield ( $\mathrm{kg} \mathrm{CH}_{4} \mathrm{~kg}^{-1} \mathrm{COD}_{\text {removed }}$ ) and the lower heating value of methane
(50 $\mathrm{MJ} \mathrm{kg}^{-1} \mathrm{CH}_{4}$ [35]), respectively. In Eq. (2), the terms $\mathrm{CH}, \mathrm{EC}_{\mathrm{CH}}$, $\mathrm{HY}$ and $\mathrm{LHV}_{\mathrm{H} 2}$ correspond to the concentration of carbohydrates in the vinasse $\left(\mathrm{kg} \mathrm{m}^{-3}\right)$, the conversion of carbohydrates (\%), the hydrogen yield ( $\mathrm{kg} \mathrm{H}_{2} \mathrm{~kg}^{-1}$ carbohydrates) and the lower heating value of hydrogen (120 MJ kg-1 $\mathrm{H}_{2}$ [36]), respectively. The COD, $\mathrm{ER}_{\mathrm{COD}}, \mathrm{MY}, \mathrm{CH}, \mathrm{EC}_{\mathrm{CH}}$ and $\mathrm{HY}$ values were obtained experimentally for the acidogenic and methanogenic reactors. The COD, ER $\mathrm{COD}_{\mathrm{C}}$ and MY values are presented for the first time in this study, whereas the values for the $\mathrm{CH}, \mathrm{EC}_{\mathrm{CH}}$ and $\mathrm{HY}$ were previously reported by Fuess et al. [17].

\section{Results and discussion}

\subsection{Acidogenic phase: Organic matter removal and hydrogen production}

The temporal profiles for the conversion of carbohydrates, production of hydrogen and production of VFAs were previously presented and discussed in detail by Fuess et al. [17]. However, a portion of the results previously reported will be briefly discussed to contextualize the combination of acidogenesis and methanogenesis. In brief, the average conversion of carbohydrates to hydrogen and VFAs was $63.9 \%$, reaching a value of $70.5 \%$ during stable operating conditions. The average values obtained for the volumetric hydrogen production rate (VHPR) and hydrogen yield (HY) were 
$789 \mathrm{~mL} \mathrm{H}_{2} \mathrm{~L}^{-1} \mathrm{~d}^{-1}$ and $1.5 \mathrm{~mol} \mathrm{H}_{2} \mathrm{~mol}^{-1} \mathrm{CH}$, respectively, including experimental data from the entire operating period (240 days). Considering the operation of the APBR under stable conditions, the values reached $1203 \mathrm{~mL} \mathrm{H}_{2} \mathrm{~L}^{-1} \mathrm{~d}^{-1}$ (VHPR) and $3.4 \mathrm{~mol} \mathrm{H}_{2} \mathrm{~mol}^{-1}$ $\mathrm{CH}$ (HY) [17], which are considerably higher than the values obtained in previous studies also based on the anaerobic fermentation of sugarcane vinasse under thermophilic conditions: $1.4 \mathrm{~mol}$ $\mathrm{H}_{2} \mathrm{~mol}^{-1} \mathrm{CH}$ (HY) and $527 \mathrm{~mL} \mathrm{H}_{2} \mathrm{~L}^{-1} \mathrm{~d}^{-1}$ (VHPR) [16]; $1.6 \mathrm{~mol}$ $\mathrm{H}_{2} \mathrm{~mol}^{-1} \mathrm{CH}$ (HY) and $762 \mathrm{~mL} \mathrm{H}_{2} \mathrm{~L}^{-1} \mathrm{~d}^{-1}$ (VHPR) [37].

The removal of organic matter in the acidogenic reactor reached approximately $20 \%$, considering both TCOD and SCOD. The values obtained are consistent with the values typically associated with the operation of acidogenic reactors [16,37], regardless of the wastewater type because such systems are characterized as organic matter-converter systems. Slight solubilization $(3.7 \%)$ of the organic matter could be observed in the acidified vinasse considering the SCOD/TCOD ratio of approximately 0.83 compared to 0.80 in the filtered raw vinasse. In contrast, an increase of 13.7-15.1\% was observed in the soluble fraction of COD by Ferraz Jr. et al. [16,37], with the SCOD/TCOD increasing from 0.73 to $0.83-0.84$ in the fermented effluent from thermophilic acidogenic reactors applied to sugarcane vinasse (in these cases, vinasse samples were also filtered through $3 \mu \mathrm{m}$ membranes prior to feeding the reactors). Such discrepancies are likely related to the HRT applied to the reactors $-7.5 \mathrm{~h}$ in this study vs. 10.2-12 $\mathrm{h}$ in Ferraz Jr. et al. [16,37], as the lower HRT applied to the APBR used in the present study could not enable an efficient solubilization of the organic matter. The washout of cells from the acidogenic reactor may also have affected the SCOD/TCOD ratio of the acidified vinasse in this study, leading to values below the levels expected.

The concentration of organic matter in the fermented vinasse applied to the methanogenic reactors reached $22.3 \pm 4.9 \mathrm{~g} \mathrm{~L}^{-1}$ (TCOD) and $18.5 \pm 4.1 \mathrm{~g} \mathrm{~L}^{-1}$ (SCOD), with average concentrations of acetic $(\mathrm{AcH})$, propionic $(\mathrm{PrH})$ and butyric $(\mathrm{BuH})$ acids of $1162 \pm 753 \mathrm{mg} \mathrm{L}^{-1}, 693 \pm 475 \mathrm{mg} \mathrm{L}^{-1}$ and $1288 \pm 808 \mathrm{mg} \mathrm{L}^{-1}$, respectively [17]. The contribution of acids to the SCOD increased from $12.5 \%$ in the raw vinasse to $34.0 \%$ in the acidified effluent. An accumulation of solids was observed in the acidified vinasse, leading to an average VSS concentration of $1162 \pm 753 \mathrm{~g} \mathrm{~L}^{-1}$. Alterations in the $\mathrm{pH}$ were also verified as a consequence of the buildup of organic acids, with an average value of $5.1 \pm 0.2$ [17] prior to the addition of sodium bicarbonate.

\subsection{Methanogenic phase: Operational stability, organic matter removal and methane production}

The results obtained for the methanogenic phase indicated a better performance of the immobilized-cell system when submitted to increasing OLR conditions. However, each increase in the OLR applied to the UASB led to the destabilization of the system, enhancing the accumulation of acids. An abrupt increase in the IA/PA ratio was observed for the UASB reactor (days 60-100, Fig. 2c) after the OLR was increased to $20 \mathrm{~kg} \mathrm{COD} \mathrm{m}^{-3} \mathrm{~d}^{-1}$ (day 54 ), leading to a peak-value of 1.05 (day 80) with a subsequent reduction in the partial alkalinity ( $\left.\sim 4000 \mathrm{mg} \mathrm{CaCO}_{3} \mathrm{~L}^{-1}, \mathrm{Fig} .2 \mathrm{~b}\right)$. The excessive concentrations of acids were removed by washing the reactor with tap water for a period equivalent to 3 times the applied HRT ( $\sim 27 \mathrm{~h}$ for the OLR of $20 \mathrm{~kg}$ COD m $\mathrm{m}^{-3} \mathrm{~d}^{-1}$ ), leading to a reduction in the IA/PA ratio (1.05-0.6, Fig. 2c). By resuming

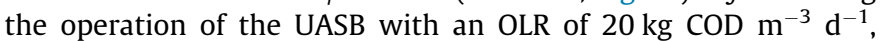
the system presented a progressive recovery to the 110th day of operation, when the IA/PA reached a stable pattern of approximately 0.3 (Fig. 2c), which is considered appropriate for high-rate anaerobic systems [32]. The limitations of the UASB reactor were related to the slurry-like aspect of the sludge (Fig. 3a) and primarily to the high concentration of inert solids in the inoculum
(Fig. 3b), which accounted for over $45 \%$ of the total mass of solids. The non-granular sludge blanket and the thick layer of inert solids likely acted as a barrier to the wastewater flow, leading to local organic overloads and promoting the accumulation of propionic acid. Nevertheless, the imposition of a new increment on the OLR (25 $\mathrm{kg}$ COD m $\mathrm{m}^{-3} \mathrm{~d}^{-1}$, day 129) did not lead to significant changes in the operational stability of the UASB, as the methanogenic biomass was already acclimatized to the fermented vinasse. Although a slight increase in the IA/PA ratio was observed (0.41, Fig. $2 \mathrm{c})$, a stable plateau close to 0.3 was again observed.

For the ASTBR, a continuous stable operation was observed after the start-up period ( d day 40 ) regardless of the OLR applied. The first increment applied to the OLR (15-20 kg COD m $\left.\mathrm{m}^{-3} \mathrm{~d}^{-1}\right)$ led to only a slight disturbance in the ASTBR, characterized by a punctual reduction in the partial alkalinity (Fig. 2b) and a slight increase in the IA/PA ratio (Fig. 2c). Even the application of OLRs as high as $30 \mathrm{~kg}$ COD m $\mathrm{m}^{-3} \mathrm{~d}^{-1}$ did not affect the stability of the system considering IA/PA ratio values between 0.2 and 0.4 (Fig. 2c). Consequently, the patterns observed for the operational stability of both methanogenic reactors reflected considerable discrepancies in the removal of organic matter (Fig. $2 d-e$ ). Focusing on the removal of TCOD, although the values obtained for the first phase $\left(\mathrm{OLR}=15 \mathrm{~kg} \mathrm{COD} \mathrm{m}^{-3} \mathrm{~d}^{-1}\right)$ reached similar levels in both reactors (Table 1 ), $\mathrm{ER}_{\mathrm{TCOD}}$ in the methanogenic phase was more than ten percentage points higher in the ASTBR for the OLR values of $20 \mathrm{~kg} \mathrm{COD} \mathrm{m}{ }^{-3} \mathrm{~d}^{-1}$ (54.9 vs. 65.7\%, Fig. $2 \mathrm{~d}$ and Table 1 ) and $25 \mathrm{~kg}$ COD m ${ }^{-3} \mathrm{~d}^{-1}$ (62.9 vs. $73.2 \%$, Fig. $2 \mathrm{~d}$ and Table 1$)$, even when stable conditions were observed in the UASB. The same pattern was observed for SCOD removal (Fig. 2e and Table 1). Considering the additional OLR increase applied to the ASTBR $\left(30 \mathrm{~kg} \mathrm{COD} \mathrm{m}^{-3}\right.$ $\mathrm{d}^{-1}$ ), the high values obtained for both $\mathrm{ER}_{\mathrm{TCOD}}$ and $\mathrm{ER}_{\mathrm{SCOD}}$ were slightly lower than the values calculated for the OLR of $25 \mathrm{~kg}$ COD $\mathrm{m}^{-3} \mathrm{~d}^{-1}$ (Table 1 ), suggesting the establishment of an operating limit of the structured-bed reactor under the temperature conditions employed. The optimal OLR condition estimated for the ASTBR varied between 26 and $28 \mathrm{~kg} \mathrm{COD} \mathrm{m}^{-3} \mathrm{~d}^{-1}$ based on the fitting of second-degree polynomial functions (Fig. 4) to the average values of $\mathrm{ER}_{\mathrm{TCOD}}$ and $\mathrm{ER}_{\mathrm{SCOD}}$.

With respect to the retention of solids within the methanogenic systems (Fig. 2f), high effluent VSS concentrations (>2000 $\mathrm{mg} \mathrm{L}^{-1}$ ) were measured in both reactors during the approximate start-up period (until the 50th day of operation), indicating the elimination of the surplus amount of biomass provided during the inoculation of the systems. Specifically, the excessive elimination of solid hindered the measurement of the TCOD; therefore, the performance of the systems could be better assessed by the SCOD removal profiles (Fig. 2e). The further increase in the applied OLR did not lead to distinct patterns in terms of solid washout in both systems, based on equivalent average values of effluent VSS, i.e., $1544 \mathrm{mg} \mathrm{L}^{-1}$ (ASTBR) and $1532 \mathrm{mg} \mathrm{L}^{-1}$ (UASB). According to the concept of UASB reactors, a higher solid retention capacity should have been observed in the sludge-bed system operated in the current study; however, the non-granular aspect of the sludge hindered the settleability of the biomass, which could explain the similar effluent VSS levels in both systems.

The amount of bicarbonate alkalinity provided in the influent stream also played a key role in obtaining stable operating conditions in both reactors. By reducing the influent concentration of $\mathrm{NaHCO}_{3}$ from 6.25 to $3 \mathrm{~g} \mathrm{~L}^{-1}$ (Fig. 2b, day 180), decreasing patterns could be observed for organic matter removal (Fig. 2d-e) and partial alkalinity (Fig. 2b) in both methanogenic systems. This strategy was applied in an attempt to reduce the effluent $\mathrm{pH}$ of the reactors (>8.3, Fig. $2 \mathrm{a}$ ) because inhibitory effects on the methanogenic activity may be observed for $\mathrm{pH}$ values of 8.3-8.5 [38]. The further increase in the amount of $\mathrm{NaHCO}_{3}$ supplied to the fermented vinasse to $6.25 \mathrm{~g} \mathrm{~L}^{-1}$ (Fig. 2b) enabled the recovery of the 

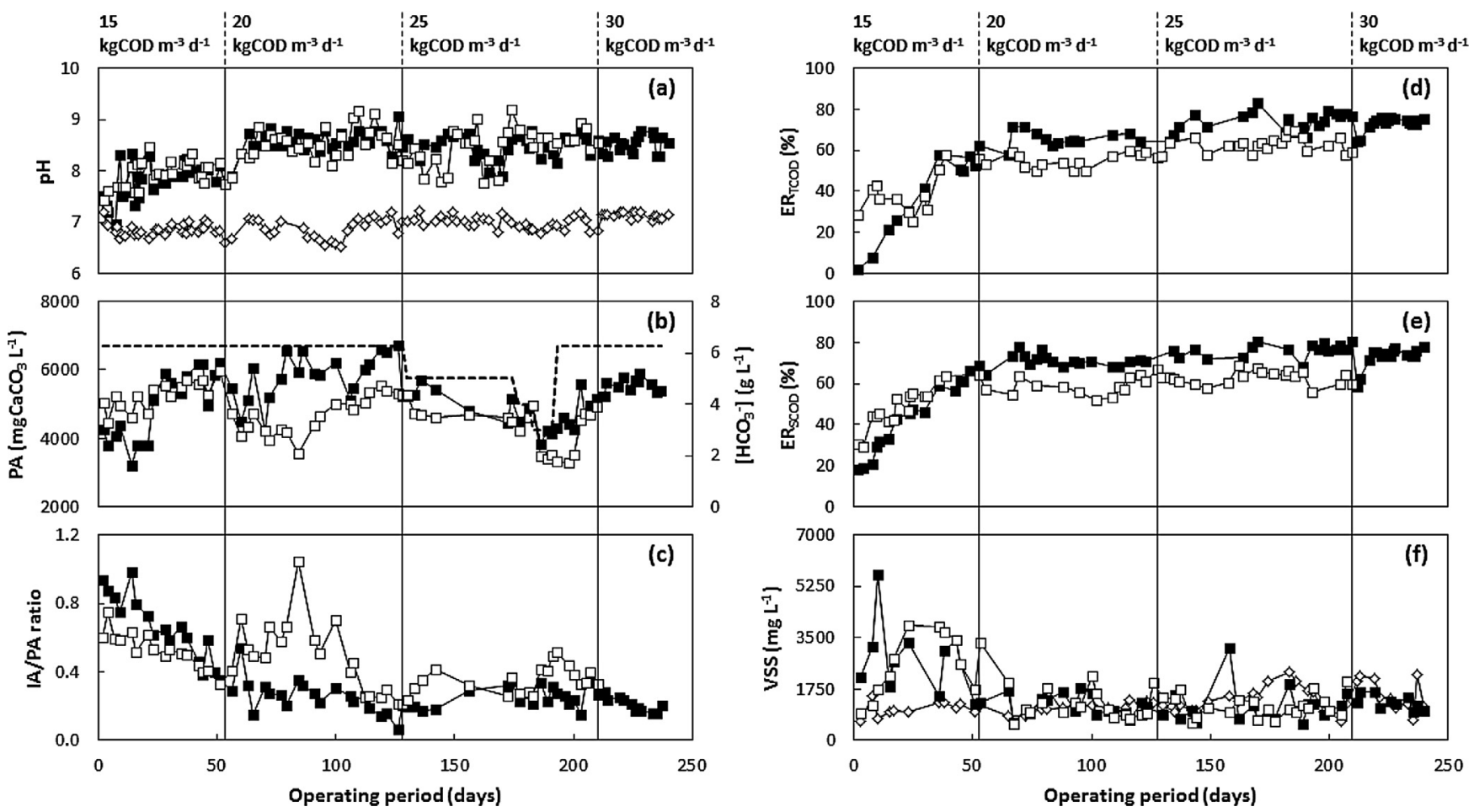

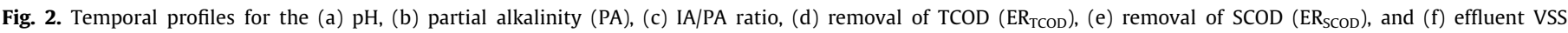
concentrations in the methanogenic reactors. Legend: influent $(-\diamond-)$, ASTBR (-口-), UASB (- $\square-)$, influent $\left[\mathrm{HCO}_{3}^{-}\right](---)$.
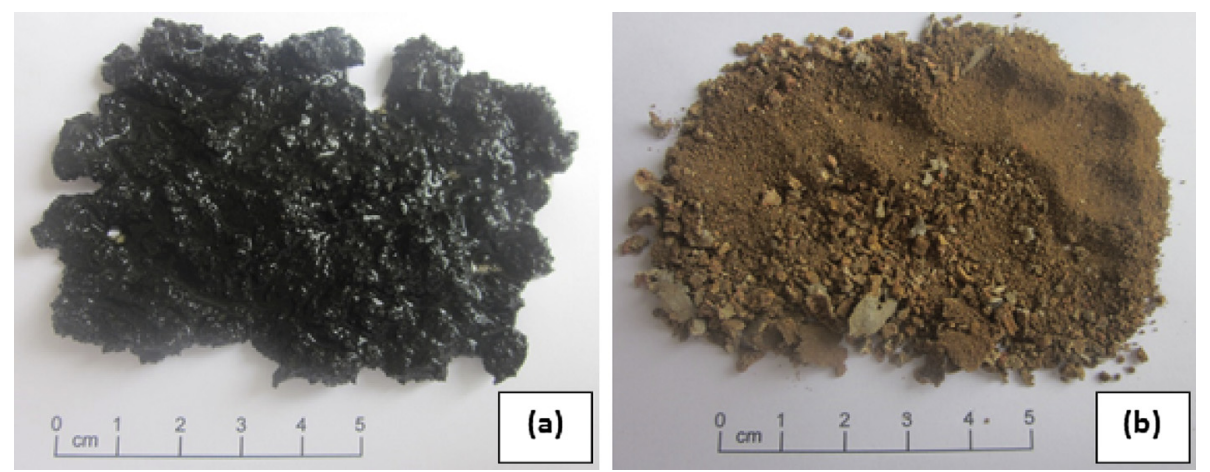

Fig. 3. Thermophilic sludge used in the inoculation of the methanogenic reactors: (a) wet sample and (b) calcined (550 $\left.{ }^{\circ} \mathrm{C}\right)$ sample.

systems regarding the removal of organic matter (Fig. $2 \mathrm{~d}-\mathrm{e}$ ) despite the discrepancy discussed above. According to Lin et al. [39], methanogenic reactors operating at high OLRs tend to exhibit greater $\mathrm{pH}$ fluctuations, justifying the need for higher concentrations of $\mathrm{NaHCO}_{3}$. Moreover, in previous studies, Ferraz Jr. et al. [11] also reported stable performance for the operation of thermophilic anaerobic systems treating sugarcane vinasse at effluent $\mathrm{pH}$ values ranging from 8.3 to 8.5. Nevertheless, the results obtained indicated that supplying the reactors with high dosages of $\mathrm{NaHCO}_{3}$ could offset the eventual limitations of applying relatively low HRT values $(<24 \mathrm{~h})$ to reactors operating at high OLRs, although economic aspects must be considered carefully when scaling up the systems. Further studies on the use of lower $\mathrm{NaHCO}_{3}$ concentrations and/or application of different approaches to provide adequate buffering to the $\mathrm{AD}$ systems treating vinasse should be carefully addressed. Phase separation may already be considered an approach to reduce the use of $\mathrm{NaHCO}_{3}$ in methanogenic systems, as the dosage used herein was half of the amount used by Ferraz Jr. et al. [11] based on the operation of a thermophilic single-phase UASB under similar OLRs. Additional strategies, such as pre-adaptation of the thermophilic inoculum to lower $\mathrm{NaHCO}_{3}$ concentrations followed by a continuous reduction on the $\mathrm{NaHCO}_{3}$ dosages from the start-up period onward, recirculation of the effluent to recycle alkalinity and use of alternative alkalizing compounds, should be considered.

Resuming the discussion on the organic matter removal, from a global perspective, i.e., considering the contribution of the acidogenic phase, the average values calculated for the $\mathrm{ER}_{\mathrm{TCOD}}$ and $\mathrm{ER}_{\mathrm{SCOD}}$ in the ASTBR exceeded $80 \%$ (Table 1) when OLRs close to the optimal conditions were applied. Although such values are similar to those associated with the operation of single-phase mesophilic reactors applied to vinasse, e.g., 88.5\% [20], 73.8\% [40], 78.1\% [41] and 80.0\% [42] for ER $_{\mathrm{TCOD}}$ values, the majority of studies under such conditions are based on the application of OLR values lower than $20 \mathrm{~kg}$ COD m $\mathrm{m}^{-3} \mathrm{~d}^{-1}$, for HRTs considerably higher than those applied in this study. Craveiro et al. [20] and Shrihari and Tare [41] applied HRTs ranging from 4.9 to $10 \mathrm{~d}$, whereas the HRT of the combined systems that were operated in 
Table 1

Performance of the methanogenic reactors regarding the removal of organic matter and methane production.

\begin{tabular}{|c|c|c|c|c|c|c|c|c|}
\hline \multirow{2}{*}{\multicolumn{2}{|c|}{ 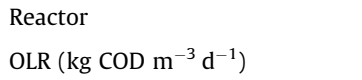 }} & \multicolumn{3}{|l|}{ UASB } & \multicolumn{4}{|l|}{ ASTBR } \\
\hline & & \multirow[t]{2}{*}{15} & \multirow[t]{2}{*}{20} & \multirow[t]{2}{*}{25} & \multirow[t]{2}{*}{15} & \multirow[t]{2}{*}{20} & \multirow[t]{2}{*}{25} & \multirow[t]{2}{*}{30} \\
\hline $\begin{array}{l}\text { Response- } \\
\text { variable }\end{array}$ & Unit & & & & & & & \\
\hline \multirow[t]{2}{*}{$\mathrm{ER}_{\mathrm{TCOD}}^{\mathrm{a}}$} & $(\%)$ & $54.8 \pm 3.7(22)$ & $54.9 \pm 3.4(27)$ & $62.9 \pm 3.7(28)$ & $55.1 \pm 4.8(23)$ & $65.7 \pm 3.8(28)$ & $73.9 \pm 4.9(29)$ & $73.2 \pm 3.6(17)$ \\
\hline & & $\mathbf{5 8 . 0}$ & 59.6 & 70.2 & 62.4 & 71.7 & 83.5 & 76.2 \\
\hline \multirow[t]{2}{*}{$\mathrm{ER}_{S C O D}{ }^{a}$} & $(\%)$ & $58.1 \pm 5.1(22)$ & $58.9 \pm 4.3(27)$ & $63.0 \pm 3.3(28)$ & $62.1 \pm 4.5(23)$ & $71.1 \pm 3.1(28)$ & $76.4 \pm 3.3(29)$ & $73.0 \pm 5.0(17)$ \\
\hline & & 64.6 & 66.6 & 69.1 & 68.7 & 78.0 & 80.7 & 77.8 \\
\hline \multirow[t]{2}{*}{$\mathrm{ER}_{\mathrm{TCOD}}^{\mathrm{b}}$} & $(\%)$ & $58.0 \pm 3.5(22)$ & $63.8 \pm 8.6(27)$ & $75.5 \pm 4.1(28)$ & $63.2 \pm 2.5(23)$ & $72.1 \pm 6.8(28)$ & $82.6 \pm 4.9(29)$ & $81.7 \pm 4.3(17)$ \\
\hline & & 62.0 & 73.1 & 82.3 & 68.6 & 80.6 & 89.3 & 84.6 \\
\hline \multirow[t]{2}{*}{$\mathrm{ER}_{S C O D}{ }^{\mathrm{b}}$} & $(\%)$ & $61.8 \pm 4.2(22)$ & $68.6 \pm 6.9(27)$ & $75.8 \pm 4.2(28)$ & $68.8 \pm 3.1(23)$ & $77.2 \pm 4.8(28)$ & $84.2 \pm 4.0(29)$ & $82.2 \pm 5.1(17)$ \\
\hline & & 66.4 & 75.2 & 84.3 & 73.0 & 84.4 & 88.7 & 86.0 \\
\hline \multirow[t]{2}{*}{ BFR } & $\left(\mathrm{mL} \mathrm{d}^{-1}\right)$ & $\begin{array}{l}6860 \pm 2842 \\
(30)\end{array}$ & $\begin{array}{l}7770 \pm 2156 \\
(49)\end{array}$ & $\begin{array}{l}14550 \pm 2106 \\
(49)\end{array}$ & $\begin{array}{l}6765 \pm 3524 \\
(35)\end{array}$ & $\begin{array}{l}16660 \pm 2339 \\
(49)\end{array}$ & $\begin{array}{l}19650 \pm 1594 \\
(45)\end{array}$ & $\begin{array}{l}18440 \pm 1860 \\
(19)\end{array}$ \\
\hline & & 10,415 & 14,915 & 19,915 & 11,675 & 21,475 & 22,310 & 23,680 \\
\hline \multirow[t]{2}{*}{ VMPR $^{\mathrm{c}}$} & $\left(\mathrm{mLCH}_{4} \mathrm{~L}^{-1} \mathrm{~d}^{-1}\right)$ & $\begin{array}{l}1040 \pm 468 \\
(24)\end{array}$ & $\begin{array}{l}1165 \pm 388 \\
(45)\end{array}$ & $2280 \pm 357(21)$ & $\begin{array}{l}1520 \pm 858 \\
(26)\end{array}$ & $3700 \pm 438(49)$ & $4505 \pm 455(32)$ & $4295 \pm 534(13)$ \\
\hline & & 1700 & 2505 & 2880 & 2710 & 4410 & 5785 & 5650 \\
\hline \multirow[t]{2}{*}{$\mathrm{MY}^{\mathrm{c}}$} & $\left(\mathrm{mLCH}_{4} \mathrm{~g}^{-1} \mathrm{CODr}\right)^{\mathrm{d}, \mathrm{e}}$ & $232 \pm 53(22)$ & $169 \pm 72(27)$ & $283 \pm 24(28)$ & $249 \pm 93(23)$ & $297 \pm 17(28)$ & $301 \pm 12(29)$ & $289 \pm 32(17)$ \\
\hline & & 334 & 300 & 313 & 315 & 328 & 319 & 329 \\
\hline
\end{tabular}

Notes: Data between parentheses indicate the number of samplings; data in bold indicate the maximum values observed in each OLR.

a Methanogenic phase.

b Global performance (acidogenic + methanogenic phases).

c Standard temperature and pressure conditions $\left(0^{\circ} \mathrm{C}, 1 \mathrm{~atm}\right)$.

d $\mathrm{CODr}=$ removed COD.

e Calculated in terms of the SCOD.
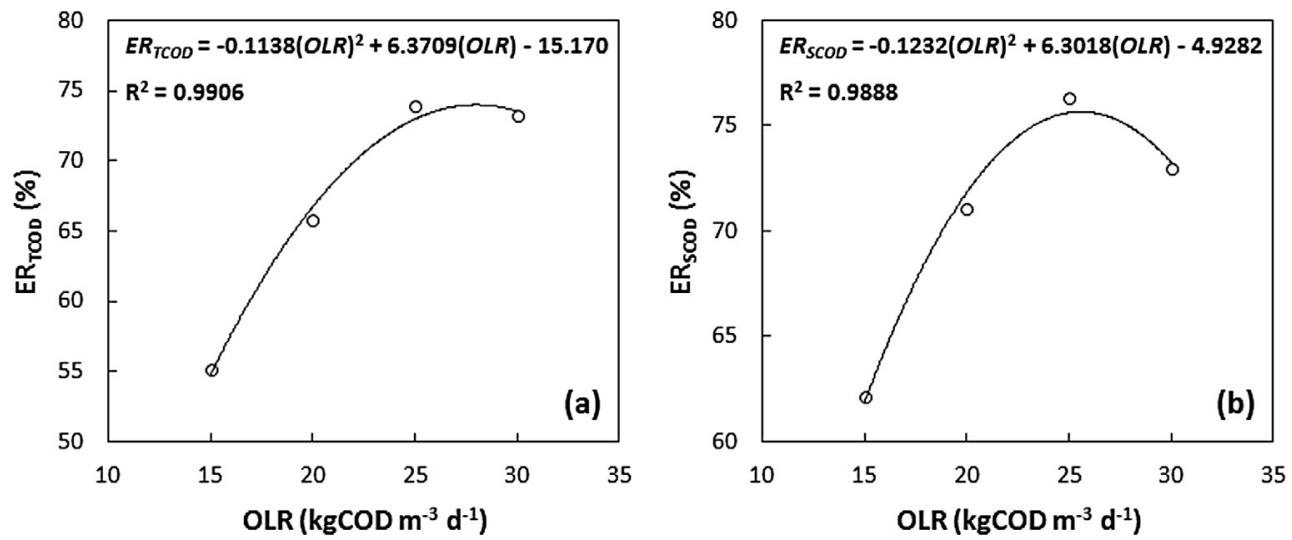

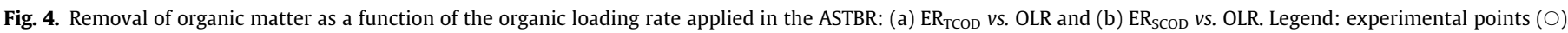
fitting curves (-

this study was approximately $29.5 \mathrm{~h}$ (1.2 days, OLR $=25 \mathrm{~kg}$ COD $\mathrm{m}^{-3} \mathrm{~d}^{-1}$ ). With respect to the application of thermophilic systems to sugarcane vinasse, in one of the few reports available, Souza et al. [21] obtained treatment performances similar to those obtained for the ASTBR $\left(\mathrm{ER}_{\mathrm{TCOD}}=71.7 \%\right)$ by operating a UASB reactor at a high OLR (26.5 $\mathrm{kg}$ COD m $\left.\mathrm{m}^{-3} \mathrm{~d}^{-1}\right)$. However, an HRT of $2 \mathrm{~d}$ was used. The levels observed for the organic matter removal in this study, even for the combined system with the UASB reactor, were considerably higher than the levels reported in other studies based on the application of single-phase thermophilic reactors to vinasse. The $\mathrm{ER}_{\mathrm{TCOD}}$ values observed in Rintala [43] and Harada et al. [22] ranged from 20 to $40 \%$ in thermophilic UASB reactors, so that the poor performance could be attributed to the presence of recalcitrant compounds in the vinasse [22] and to the type of seed sludge used, which was collected from a mesophilic reactor in Rintala [43]. Recent studies of the application of AD to sugarcane vinasse also failed to associate satisfactory performance with compact systems, usually attributing high COD removal levels (70$80 \%$ ) to relatively high HRTs (2.8-1.8 days) and low OLRs (0.2$\left.11.5 \mathrm{~kg} \mathrm{COD} \mathrm{m}^{-3} \mathrm{~d}^{-1}\right)$ [26] or high OLRs (25-26.2 $\mathrm{kg} \mathrm{COD} \mathrm{m}^{-3}$ $\mathrm{d}^{-1}$ ) to low COD removal efficiencies (51.0-60.7\%) [11,25]. It should be noted, however, that in vinasses obtained directly from molasses fermentation, which is typical for the Indian sucro-alcohol industry, the concentration of organic matter reaches much higher levels ( $\left.C O D=57.6-130 \mathrm{~g} \mathrm{~L}^{-1},[22,40-43]\right)$ than the values commonly observed in the Brazilian industry (COD $\left.=28.3-45 \mathrm{~g} \mathrm{~L}^{-1}[11,17,19-21,26]\right)$, in which mixtures of molasses and juice are primarily used. Thus, despite the common feedstock, i.e., sugarcane, the composition of vinasse may be quite different, and therefore, the relevance of the results obtained herein is more evident when considering the studies of Ferraz Jr. et al. [11], Costa et al. [19], Craveiro et al. [20], Souza et al. [21] and Barros et al. [26], as references.

The pre-acclimatization of the seed sludge used in this study to thermophilic conditions and sugarcane vinasse may partially explain the high performance of the ASTBR in that the elimination of the inert solids during the inoculation of this reactor provided adequate conditions for the methanogenic archaea by preventing the accumulation of acids. Molecular analyses (supplementary data) indicated a similar microbial composition (low number of 
unique operational taxonomic units - OTUs) for both methanogenic reactors; thus, the observed performance discrepancies likely resulted from the design and operating aspects of the systems. The importance of the phase separation for both systems should also be highlighted, as the destabilization of single-phase thermophilic systems often results from the imbalance between acidogenic and methanogenic microbial populations, enhancing the accumulation of organic acids [44].

With respect to the production of biogas and methane, the results corroborate the behavior previously discussed for the operational stability and organic matter removal, indicating the superior performance of the ASTBR compared to the UASB reactor. Although the UASB reactor recovered the operational stability during the long-term operation, the methane production was considerably lower than in the ASTBR (Table 1 and Fig. 5). For an OLR of $25 \mathrm{~kg}$ COD m $\mathrm{m}^{-3} \mathrm{~d}^{-1}$, the average values obtained for the BFR and VMPR were 25 and 50\% lower in the UASB reactor (Table 1 ), respectively, indicating higher discrepancies compared to that observed for the removal of organic matter. The sludge blanket conformation may also be associated with the limitations on biogas production in the UASB by acting as a barrier to releasing the bubbles from the bulk liquid. The low turbulence resulting from the low upflow velocity applied to the bench-scale reactor $\left(0.02-0.03 \mathrm{~m} \mathrm{~h}^{-1}\right)$ also contributed to entrap the biogas bubbles within the sludge and inert solids. Conversely, biogas upflow velocities ranging between 0.06 and $0.12 \mathrm{~m} \mathrm{~h}^{-1}$ were estimated for the UASB reactor; therefore, the mass transfer limitations resulting from the high concentrations of accumulated inert solids could be partially offset. In fact, the 2-fold greater VMPR observed when applying an OLR of $25 \mathrm{~kg} \mathrm{COD} \mathrm{m}^{-3} \mathrm{~d}^{-1}\left(2280 \mathrm{~mL} \mathrm{CH}_{4} \mathrm{~L}^{-1} \mathrm{~d}^{-1}\right)$ - compared to an OLR of $20 \mathrm{~kg} \mathrm{COD} \mathrm{m} \mathrm{m}^{-3} \mathrm{~d}^{-1}\left(1165 \mathrm{~mL} \mathrm{CH}_{4} \mathrm{~L}^{-1} \mathrm{~d}^{-1}\right)$ - suggests a positive effect from the turbulence generated by biogas production within the sludge bed.

The values calculated for the methane yield, specifically for the

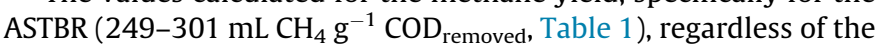
OLR applied, also reached levels higher than those reported in the literature considering the application of AD to raw vinasse: $210-$ $290 \mathrm{~mL} \mathrm{CH}_{4} \mathrm{~g}^{-1} \mathrm{COD}_{\text {removed }}$ (Bories et al. [40] - molasses vinasse, operation at $37^{\circ} \mathrm{C}$ ), $170 \mathrm{~mL} \mathrm{CH}_{4} \mathrm{~g}^{-1} \mathrm{COD}_{\text {removed }}$ (Shrihari and Tare [41] - molasses vinasse, operation at $\left.35^{\circ} \mathrm{C}\right), 179-234 \mathrm{~mL} \mathrm{CH}_{4} \mathrm{~g}^{-1}$ $\mathrm{COD}_{\text {removed }}$ (Ferraz Jr. et al. [11] - juice/molasses vinasse, operation at $55^{\circ} \mathrm{C}$ ) and $133-185 \mathrm{~mL} \mathrm{CH}_{4} \mathrm{~g}^{-1} \mathrm{COD}_{\text {removed }}$ (Barros et al. [26] - operation at mesophilic temperature range). Such results corroborate the establishment of conditions more favorable to methanogenesis in $\mathrm{AD}$ systems operated with phase separation based on the ready availability of acetate to the archaea [10].

\subsection{VFA profiles for the methanogenic phase}

The temporal profiles of VFA concentrations in the effluent from both methanogenic reactors are shown in Fig. 6 . The concentrations of $\mathrm{PrH}$ accounted for approximately $60-80 \%$ of the total VFA levels measured in the vinasse collected from the UASB reactor for the OLR values of 20 and $25 \mathrm{~kg}$ COD m $\mathrm{m}^{-3} \mathrm{~d}^{-1}$ (Table 2). However, the washing of the UASB with tap water promoted an increase in the concentration of $\mathrm{AcH}$ ( $\sim$ day 80 , Fig. $6 \mathrm{a}$ ) in the effluent, corroborating the aforementioned performance recovery. With respect to the ASTBR, the concentrations of $\mathrm{PrH}$ reached approximately $40-50 \%$ of those observed for the UASB (OLR of 20 and $25 \mathrm{~kg}$ COD $\mathrm{m}^{-3} \mathrm{~d}^{-1}$, Table 2). Although such concentrations presented a decreasing pattern with the application of increasing OLRs to the ASTBR (Fig. 6b and Table 2), a slight increase was observed for the

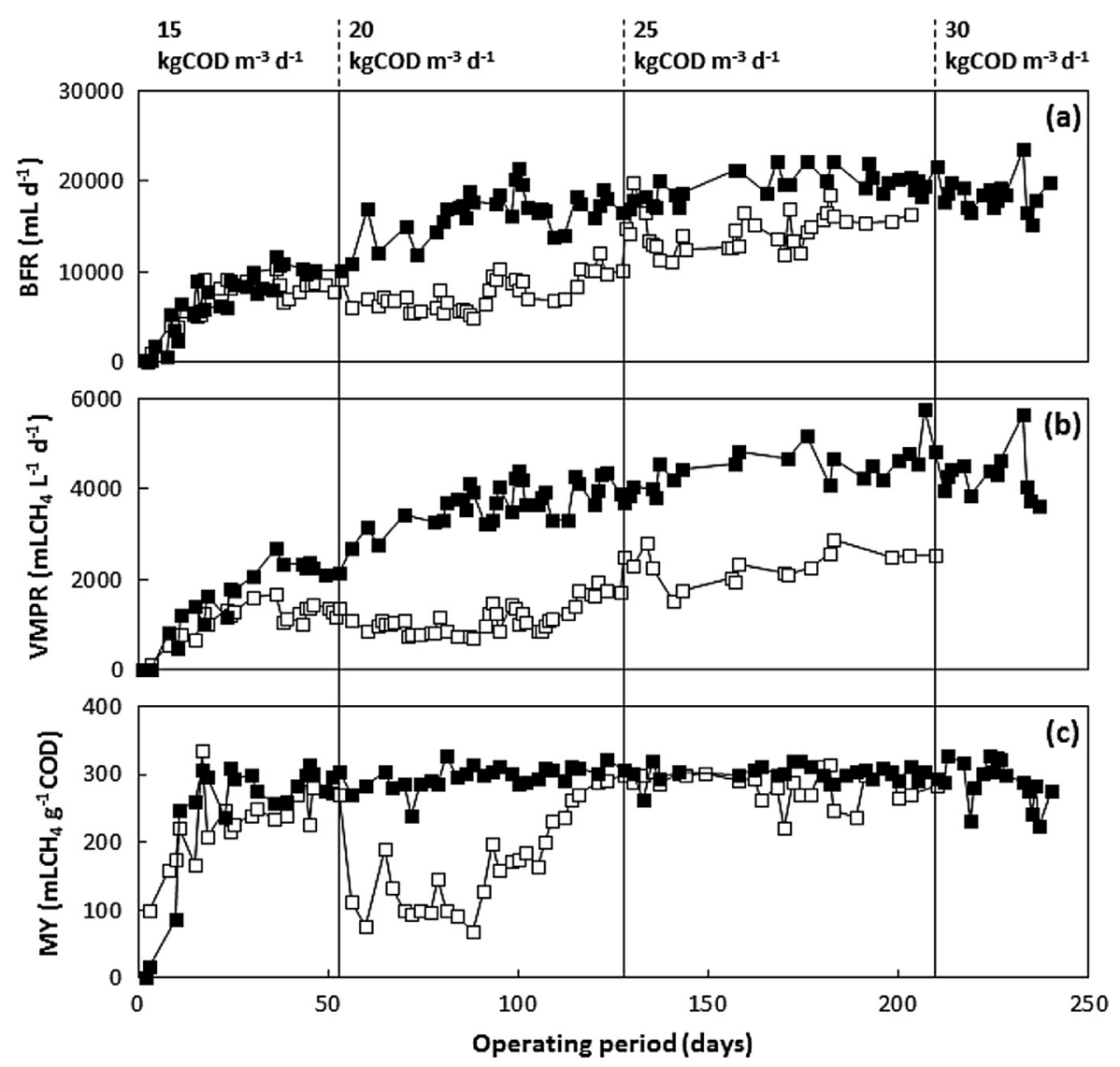

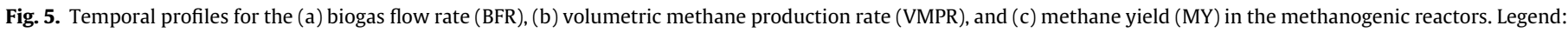
ASTBR (-ם-), UASB (- $\square-)$. 

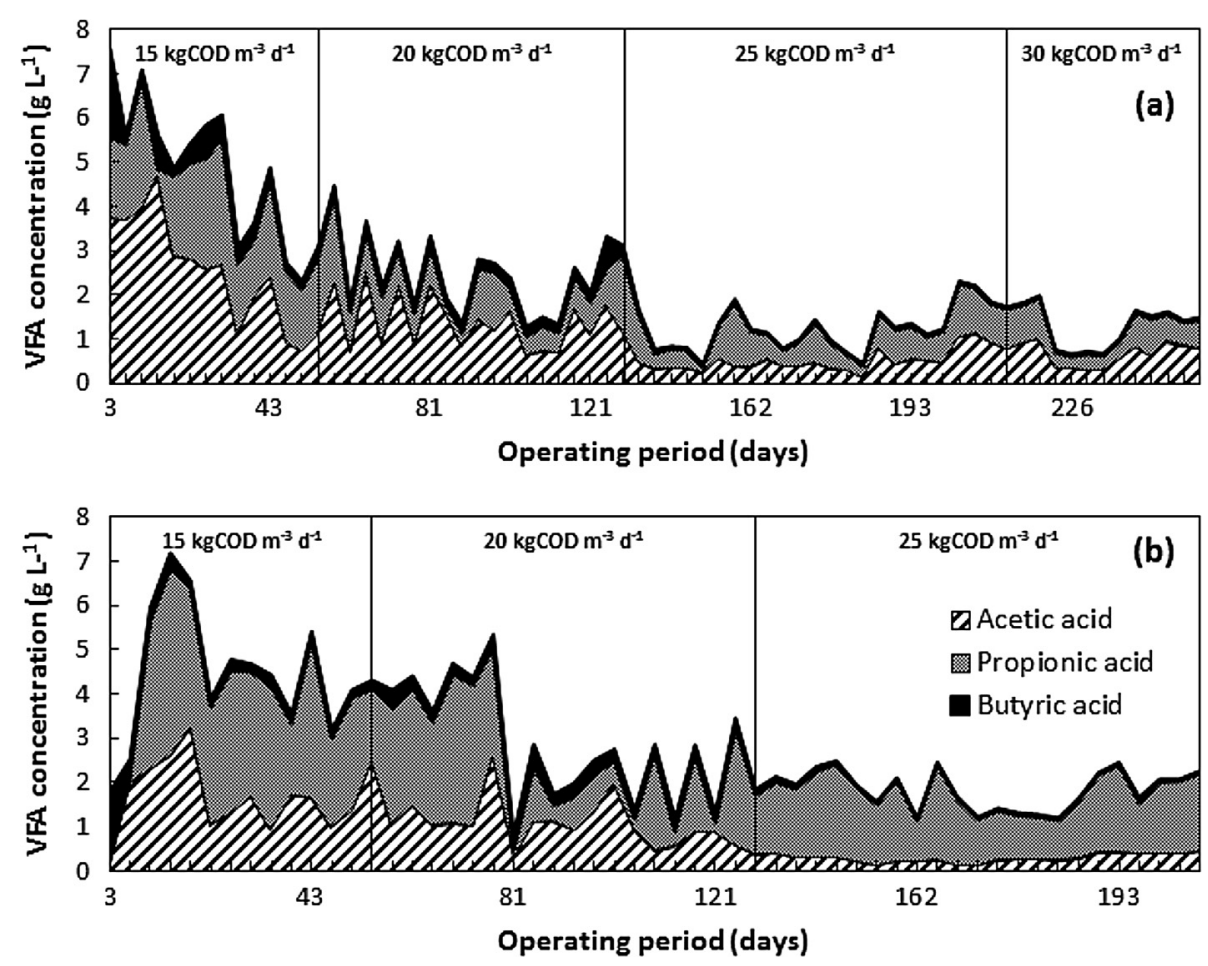

Fig. 6. VFA concentration temporal profiles for the anaerobically treated vinasse: (a) ASTBR and (b) UASB.

Table 2

VFA concentration in the anaerobically treated vinasse samples.

\begin{tabular}{|c|c|c|c|c|c|c|c|}
\hline \multirow{2}{*}{$\begin{array}{l}\text { Reactor } \\
\left.\text { OLR ( } \mathrm{kg} \text { COD } \mathrm{m}^{-3} \mathrm{~d}^{-1}\right)\end{array}$} & \multicolumn{3}{|l|}{ UASB } & \multicolumn{4}{|l|}{ ASTBR } \\
\hline & 15 & 20 & 25 & 15 & 20 & 25 & 30 \\
\hline $\mathrm{AcH}$ & $1250 \pm 1031$ & $831 \pm 437(19)$ & $286 \pm 92(22)$ & $2145 \pm 1569$ & $917 \pm 508(19)$ & $458 \pm 238(22)$ & $649 \pm 261(14)$ \\
\hline$\left(\mathrm{mg} \mathrm{L}^{-1}\right)$ & 3236 & 1965 & 442 & 4663 & 1743 & 1093 & 979 \\
\hline $\mathrm{PrH}$ & $2357 \pm 1346$ & $1552 \pm 1111(19)$ & $1490 \pm 398(22)$ & $1767 \pm 840$ & $879 \pm 468$ (19) & $683 \pm 325(22)$ & $638 \pm 249(14)$ \\
\hline$\left(\mathrm{mg} \mathrm{L}^{-1}\right)$ & 4222 & 3372 & 2155 & 2977 & 2016 & 1461 & 948 \\
\hline $\mathrm{BuH}$ & $311 \pm 333(14)$ & $258 \pm 88(19)$ & $64 \pm 24(22)$ & $468 \pm 489(14)$ & $227 \pm 119$ (19) & $60 \pm 17(22)$ & $55 \pm 8$ \\
\hline$\left(\mathrm{mg} \mathrm{L}^{-1}\right)$ & 1445 & 493 & 120 & 2015 & 711 & 113 & 69 \\
\hline $\mathrm{AcH}+\mathrm{PrH}+\mathrm{BuH}$ & $3918 \pm 1872(14)$ & $2641 \pm 1112(19)$ & $1840 \pm 448(22)$ & $4380 \pm 2088$ & $2023 \pm 666(19)$ & $1201 \pm 508(22)$ & $1342 \pm 480(14)$ \\
\hline$\left(\mathrm{mg} \mathrm{L}^{-1}\right)$ & 7176 & 4685 & 2478 & 7570 & 3314 & 2297 & 1973 \\
\hline
\end{tabular}

Notes: Data between parentheses indicate the number of samplings; data in bold indicate the maximum values observed in each OLR

relative proportion of $\operatorname{PrH}$, i.e., $40 \%\left(\mathrm{OLR}=15 \mathrm{~kg} \mathrm{COD} \mathrm{m}^{-3} \mathrm{~d}^{-1}\right)$ to $50 \%\left(\mathrm{OLR}=30 \mathrm{~kg}\right.$ COD $\left.\mathrm{m}^{-3} \mathrm{~d}^{-1}\right)$. Several studies [21-24,45] reported the accumulation of $\mathrm{PrH}$ in the thermophilic anaerobic reactors, indicating its degradation as the rate-limiting step in such systems. In high-rate systems, the conversion of $\mathrm{PrH}$ to $\mathrm{AcH}$ is typically the first metabolic pathway subjected to interferences when imbalance conditions are established in the reactor [23] because this route demands more energy $\left(\mathrm{AG}^{\circ}=+62.3 \mathrm{~kJ} \mathrm{~mol}^{-1}, 55^{\circ} \mathrm{C}\right)$ than the conversion of $\mathrm{BuH}$ to $\mathrm{AcH}\left(\mathrm{AG}^{\circ}=+37.9 \mathrm{~kJ} \mathrm{~mol}^{-1}, 55^{\circ} \mathrm{C}\right)[18]$. However, the accumulation of $\mathrm{PrH}$ does not necessarily imply the collapse of the thermophilic AD systems, as observed during the operation of the ASTBR, and thus, the provision of adequate concentrations of $\mathrm{NaHCO}_{3}$ must be carefully considered.

\subsection{Soluble phase and global COD-based mass balances}

Monitoring data from the operation of the reactors were used to calculate COD-based mass balances for the soluble phase and global performance of the systems. Data regarding the raw and acidified vinasses were previously presented and discussed in detail by Fuess et al. [17]. Therefore, this section focuses on the mass bal- ances obtained for the methanogenic phase, i.e., the ASTBR and UASB. Two distinct mass balances were calculated for each reactor: the first (soluble phase mass balance - SPMB) considered the distribution of the soluble compounds in the sugarcane vinasse samples collected from both the ASTBR and UASB, whereas the second also included the production of methane and suspend solids (biomass) in addition to the soluble compounds (global mass balance - GMB).

Table 3 provides the contribution of each group of analyzed compounds to the mass balances according to the OLR applied to the reactors. An increasing pattern could be observed for the SPMB when the OLR applied to the ASTBR increased from 15 to $30 \mathrm{~kg}$ COD $\mathrm{m}^{-3} \mathrm{~d}^{-1}$, ranging from 51.8 to $67.3-69.4 \%$ (Table 3 ). Such values are considerably higher than those previously reported for the raw (36.9\%) and acidified vinasses (43.9\%) [17], which indicates the conversion of compounds that were not identified into organic acids. The non-identified fraction likely results from the presence of melanoidins based on the high color observed in the treated vinasse. Melanoidins are macromolecular compounds that exhibit antioxidant properties, leading to a recalcitrant character in the biological conversion [46]. The lower values regarding the SPMB 
Table 3

Soluble phase and global COD-based mass balances for the methanogenic phase.

\begin{tabular}{|c|c|c|c|c|c|c|c|c|}
\hline \multirow[t]{2}{*}{ Mass balance } & \multirow[t]{2}{*}{$\operatorname{OLR}\left(\mathrm{kg} \mathrm{COD} \mathrm{m}^{-3} \mathrm{~d}^{-1}\right)$} & \multicolumn{7}{|c|}{ Proportion in the measured COD (\%) } \\
\hline & & Carbohydrates & Metabolites $^{\mathrm{a}}$ & SCOD effluent & Methane & VSS effluent & Recovered fraction $^{\mathrm{b}}$ & Non-recovered fraction \\
\hline \multirow[t]{4}{*}{ SPMB (ASTBR) } & 15 & $3.9 \pm 1.1$ & $47.9 \pm 13.5$ & - & - & - & $51.8 \pm 13.4$ & $48.1 \pm 13.4$ \\
\hline & 20 & $7.2 \pm 1.0$ & $62.1 \pm 17.7$ & - & - & - & $69.3 \pm 18.0$ & $30.7 \pm 18.0$ \\
\hline & 25 & $8.5 \pm 1.4$ & $60.9 \pm 21.7$ & - & - & - & $69.4 \pm 22.4$ & $30.6 \pm 22.5$ \\
\hline & 30 & $10.2 \pm 0.9$ & $57.0 \pm 4.8$ & - & - & - & $67.3 \pm 4.9$ & $32.7 \pm 4.9$ \\
\hline \multirow[t]{3}{*}{ SPMB (UASB) } & 15 & $3.4 \pm 0.7$ & $53.3 \pm 22.4$ & - & - & - & $56.7 \pm 22.4$ & $43.3 \pm 22.4$ \\
\hline & 20 & $4.4 \pm 0.8$ & $56.8 \pm 17.8$ & - & - & - & $61.2 \pm 17.9$ & $38.8 \pm 17.9$ \\
\hline & 25 & $4.8 \pm 0.6$ & $47.9 \pm 5.9$ & - & - & - & $52.7 \pm 6.3$ & $47.3 \pm 6.3$ \\
\hline \multirow[t]{4}{*}{ GMB (ASTBR) } & 15 & - & - & $46.5 \pm 15.6$ & $31.6 \pm 18.1$ & $14.9 \pm 7.6$ & $93.1 \pm 8.0$ & $6.9 \pm 8.0$ \\
\hline & 20 & - & - & $28.7 \pm 3.1$ & $53.2 \pm 5.2$ & $8.2 \pm 1.4$ & $90.2 \pm 3.5$ & $9.8 \pm 3.5$ \\
\hline & 25 & - & - & $24.9 \pm 5.0$ & $58.5 \pm 13.9$ & $10.0 \pm 6.7$ & $93.3 \pm 13.6$ & $6.7 \pm 13.6$ \\
\hline & 30 & - & - & $22.5 \pm 4.8$ & $49.8 \pm 5.7$ & $10.0 \pm 1.6$ & $82.3 \pm 7.6$ & $17.7 \pm 7.6$ \\
\hline \multirow[t]{3}{*}{ GMB (UASB) } & 15 & - & - & $42.4 \pm 11.5$ & $29.1 \pm 12.9$ & $6.3 \pm 1.5$ & $77.6 \pm 8.1$ & $22.4 \pm 8.1$ \\
\hline & 20 & - & - & $41.1 \pm 7.1$ & $36.6 \pm 25.8$ & $8.0 \pm 2.1$ & $85.7 \pm 21.4$ & $14.3 \pm 21.4$ \\
\hline & 25 & - & - & $34.6 \pm 8.2$ & $38.5 \pm 5.4$ & $9.6 \pm 1.0$ & $82.7 \pm 7.7$ & $17.3 \pm 7.7$ \\
\hline
\end{tabular}

Notes:

a Ethanol, acetic acid, propionic acid and butyric acid.

b Carbohydrates + metabolites for the SPMB, SCOD effluent + methane + VSS effluent for the GMB.

for the UASB (52.7-61.2\%, Table 3) are likely related to the unstable operation of this system, which led to a less efficient conversion of the organic substrates into VFAs.

With respect to the GMB, the ratio between the TCOD estimated (i.e., SCOD + methane + VSS) and the TCOD measured presented the same pattern compared to the SPMB, with less favorable scenarios observed for the UASB. GMB reached values typically exceeding $90 \%$ for the ASTBR, whereas the levels observed for the UASB ranged from $80 \%$ to $85 \%$ (Table 3 ). The losses in the COD recovery for the UASB likely resulted from the entrapment of biogas bubbles within the sludge blanket, as the fraction of methane recovered was less than $40 \%$ of the influent TCOD (Table 3 ) regardless of the applied OLR. In contrast, the recovery of methane in the ASTBR exceeded 50\% when the system reached the operational stability, leading to a peak of $58.5 \%$ for an OLR of $25 \mathrm{~kg}$ COD m $\mathrm{m}^{-3} \mathrm{~d}^{-1}$ (Table 3).

\subsection{Energetic potential of sugarcane vinasse}

The energetic potential of the vinasse was based on the experimentally obtained hydrogen and methane yield values. Regarding the contribution of methane, estimates considered only data from the ASTBR (OLR of $25 \mathrm{~kg} \mathrm{COD} \mathrm{m}^{-3} \mathrm{~d}^{-1}$ ) due to the instabilities associated with the operation of the UASB. Furthermore, the conversion of the biogas in generators and similar systems (e.g., reciprocating engines, boilers and turbines) was not considered, i.e., the losses inherent to such systems were not included. Four scenarios were analyzed: C1 - EP only from the methane in the combined system; C2 - EP from methane and hydrogen, considering average values for the $\mathrm{HY}$ and $\mathrm{EC}_{\mathrm{CH}}$ [17]; $\mathrm{C} 3$ - $\mathrm{EP}$ from methane and hydrogen, for optimal values of $\mathrm{HY}$ and $\mathrm{EC}_{\mathrm{CH}}$ [17]; and $\mathrm{C} 4$ - EP from methane in a single-phase thermophilic AD system. Data applied to estimates in C4 were obtained by Ferraz Jr. et al. [11], i.e., $\mathrm{ER}_{\mathrm{COD}}=60.7 \%$ and $\mathrm{MY}=234 \mathrm{~mL} \mathrm{CH}_{4} \mathrm{~g}^{-1} \mathrm{COD}$. Ferraz Jr. et al. [11] used sugarcane vinasses from the same distillery sampled in this study, and the performance data considered were obtained under

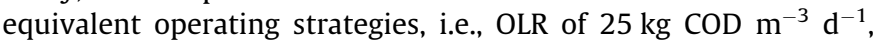
thermophilic conditions $\left(55^{\circ} \mathrm{C}\right)$ and $\mathrm{NaHCO}_{3}$ supply.

EP values of $177.7,181.5$ and $187.2 \mathrm{MJ} \mathrm{m}_{\text {vinasse }}^{-3}$ were estimated for scenarios C1, C2 and C3 (Table 4), respectively, reaching similar values even when optimal conditions were considered for the acidogenic phase. Such a pattern results from the low contribution of hydrogen to the EP of vinasse, i.e., 2.1\% in C2 and 5.1\% in C3. Similarly, the energy from hydrogen accounted for less than $6 \%$ of the
EP from cassava vinasse in Luo et al. [7], who also considered the operation of a thermophilic system. Peixoto et al. [47] also reported that hydrogen represented only $2.5 \%$ of the energy yield from the application of combined AD to vinasse from sugarcane using batch reactors under mesophilic conditions. Despite such results, the estimates presented here demonstrate that the operation of the acidogenic phase under optimal conditions could potentially provide a $150 \%$ increase in the contribution of hydrogen to the EP of vinasse. Furthermore, the energy extraction in the combined AD system, regardless of the use of hydrogen, was at least $23.4 \%$ higher than the value calculated for the single-phase reactor $(\mathrm{EP}=144.0 \mathrm{MJ} \mathrm{m}=3$ vinasse, C4, Table 4). This discrepancy results from the improvements in the biodegradability of the acidified effluents, as previously discussed. Luo et al. [7] observed an $11 \%$ increase in the energy extraction from cassava vinasse by comparing a two-phase and a singlephase AD system, whereas in Nasr et al. [8], this value reached $18.5 \%$ based on the use of corn vinasse as the substrate. With respect to the application of other types of wastewaters, lower values regarding the energy extraction in combined systems (10-13.4\%) were reported in Lee and Chung [10] and Massanet-Nicolau et al. [9] considering the conversion of food waste and lignocellulosic materials (grass), respectively.

Considering a wider analysis, the EP regarding the total volume of vinasse generated within the 2014/2015 sugarcane season could reach 17.6 million $\mathrm{MWh}$, which is comparable to the energy effectively produced from the combustion of bagasse (20.0 million MW h [48]) for the 2009/2010 season. Such an estimate considered the total production of ethanol in the 2014/2015 season (26.88 million cubic meters [49]), an average generation rate of $13 \mathrm{~L}$ of

Table 4

Energetic potential estimated for the sugarcane vinasse.

\begin{tabular}{llll}
\hline \multirow{2}{*}{ Scenario } & \multicolumn{2}{l}{ Energetic potential (MJ m minasse } \\
\cline { 2 - 4 } & Hydrogen & Methane & Global \\
\hline C1 & - & 177.7 & 177.0 \\
C2 & $3.8(2.1 \%)$ & 177.7 & 181.5 \\
C3 & $9.5(5.1 \%)$ & 177.7 & 187.2 \\
C4 & - & 144.0 & 144.0 \\
\hline
\end{tabular}

Notes: C1 = combined system, use of methane; $\mathrm{C} 2$ = combined system, use of hydrogen (average performance [17]) and methane; $C 3=$ combined system, use of hydrogen (optimal conditions [17]) and methane; $C 4$ = single-phase system, use of methane [11]. The numbers between parentheses indicate the contribution of hydrogen to the global energetic potential. 
vinasse per liter of ethanol [12] and the energy yield calculated for sugarcane vinasse in scenario C2 (181.5 MJ minasse, Table 4). The EP of vinasse under the conditions used could also reach approximately $20 \%$ of the total electrical energy generated in Itaipu (87.8 million MW $\mathrm{h}[50])$, the second largest hydropower plant in the world. In this context, the results obtained herein indicate that the direct land application of vinasse to agricultural fields characterizes an underutilization of a highly energetic raw material, and thus, the combined acidogenic-methanogenic anaerobic process should be considered the core treatment technology in ethanol biorefineries to enable higher bioenergy recovery levels from the raw material.

\section{Conclusions}

The results obtained herein demonstrated the feasibility of applying both the anaerobic process with phase separation and a structured-bed reactor, specifically as the methanogenic reactor, to the treatment of sugarcane vinasse. The advantages of immobilized cell growth, in association with the use of an acclimatized sludge under thermophilic conditions and sugarcane vinasse, led to peak organic matter removal values exceeding $80 \%$ in the methanogenic phase based on a stable long-term operation (240 days) of the structured-bed reactor for an OLR as high as $30 \mathrm{~kg}$ COD m $\mathrm{m}^{-3} \mathrm{~d}^{-1}$. However, the application of similar conditions to the UASB reactor yielded severe performance losses, leading to the accumulation of VFAs for every increase in the OLR as a direct consequence of high levels of inert solids in the sludge bed. Molecular analyses indicated low numbers of unique operational taxonomic units for both methanogenic reactors, and five of eight identified genera (060F05-B-SD-P93, Anaerobaculum, Methanosarcina, Syntrophaceticus, and Thermodesulfovibrio) were observed in both reactors. Thus, the observed performance discrepancies likely resulted from design and operating aspects of the systems. Regardless of the type of methanogenic reactor, supplying bicarbonate to control system alkalinity also proved to be a key factor in obtaining stable performance to offset the eventual limitations of applying relatively low hydraulic retention times $(<24 \mathrm{~h})$ to the reactors. With respect to the global performance, i.e., the acidogenic and methanogenic phases, average COD removal values exceeding $80 \%$ were observed, in association with an energetic potential of 181.5 MJ for each cubic meter of sugarcane vinasse from both hydrogen and methane. Thus, the implementation of anaerobic combined processes with the structured-bed reactor as the methanogenic phase should be encouraged in ethanol plants for enhancing both organic matter degradation and bioenergy recovery.

\section{Acknowledgments}

The authors are grateful to the Fundação de Amparo à Pesquisa do Estado de São Paulo (Fapesp) (grant numbers 2009/15984-0, 2012/15606-9, 2013/15665-8, and 2015/21650-9) for supporting the development of this study, to Mr. Claudio Frazão Araújo and Ms. Michele Fernanda Pires from Usina São Martinho for providing the sugarcane vinasse samples, and to the provision of time at the NGS facility at CTBE/CNPEM.

\section{Appendix A. Supplementary material}

Supplementary data associated with this article can be found, in the online version, at http://dx.doi.org/10.1016/j.apenergy.2016. 12.071 .

\section{References}

[1] Chan YJ, Chong MF, Law CL, Hassell DG. A review on anaerobic-aerobic treatment of industrial and municipal wastewater. Chem Eng J 2009;155:1-8.
[2] van Lier JB, van der Zee FP, Frijters CTMJ, Ersahin ME. Celebrating 40 years anaerobic sludge bed reactors for industrial wastewater treatment. Rev Environ Sci Biotechnol 2015;14:681-702.

[3] Bailey JE, Ollis DF. Biochemical engineering fundamentals. 2nd ed. New York: McGraw-Hill; 1986.

[4] Poggi-Varaldo HM, Munoz-Paez KM, Escamilla-Alvarado C, Robledo-Narváez PN, Ponce-Noyola MT, Calva-Calva G, et al. Biohydrogen, biomethane and bioelectricity as crucial components of biorefinery of organic wastes: a review. Waste Manage Res 2014;32:353-65.

[5] Yang X, Choi HS, Park C, Kim SW. Current states and prospects of organic waste utilization for biorefineries. Renew Sustain Energy Rev 2015;49:335-49.

[6] Hallenbeck PC. Fermentative hydrogen production: principles, progress, and prognosis. Int J Hydrogen Energy 2009;34:7379-89.

[7] Luo G, Xie L, Zhou Q, Angelidaki I. Enhancement of bioenergy production from organic wastes by two-stage anaerobic hydrogen and methane production process. Bioresour Technol 2011;102:8700-6.

[8] Nasr N, Elbeshbishy E, Hafez H, Nakhla G, El Naggar MH. Comparative assessment of single-stage and two-stage anaerobic digestion for the treatment of thin vinasse. Bioresour Technol 2012:111:122-6.

[9] Massanet-Nicolau J, Dinsdale R, Guwy A, Shipley G. Utilising biohydrogen to increase methane production, energy yields and process efficiency via two stage anaerobic digestion of grass. Bioresour Technol 2015;189:379-83.

[10] Lee YW, Chung J. Bioproduction of hydrogen from food waste by pilot-scale combined hydrogen/methane fermentation. Int J Hydrogen Energy 2010;35:11746-55.

[11] Ferraz Jr ADN, Koyama MH, Araújo Jr MM, Zaiat M. Thermophilic anaerobic digestion of raw sugarcane vinasse. Renew Energy 2016;89:245-52.

[12] Fuess LT, Garcia ML. Implications of vinasse land disposal: a critical review on the impacts of fertigation. J Environ Manage 2014;145:210-29.

[13] Salomon KR, Lora EES, Rocha MH, del Olmo OA. Cost calculations for biogas from vinasse biodigestion and its energy utilization. Sugar Ind 2011;136 (4):217-23.

[14] Moraes BS, Junqueira TL, Pavanello LG, Cavalett O, Mantelatto PE, Bonomi A et al. Anaerobic digestion of vinasse from sugarcane biorefineries in Brazil from energy, environmental, and economic perspectives: profit or expense? Appl Energy 2014;113:825-35.

[15] Fuess LT, Garcia ML. Bioenergy from vinasse anaerobic digestion to enhance the energy balance ratio of ethanol production. J Environ Manage 2015;162:102-14.

[16] Ferraz Jr ADN, Wenzel J, Etchebehere C, Zait M. Effect of organic loading rate on hydrogen production from sugarcane vinasse in thermophilic acidogenic packed bed reactors. Int J Hydrogen Energy 2014;39:16852-62.

[17] Fuess LT, Kiyuna LSM, Garcia ML, Zaiat M. Operational strategies for the longterm biohydrogen production from sugarcane vinasse in continuous acidogenic packed-bed reactor. Int J Hydrogen Energy 2016;41:8132-45.

[18] Amani T, Nosrati M, Mousavi SM, Elyasi Sh. Study of microbiological and operational parameters in thermophilic syntrophic degradation of volatile fatty acids in an upflow anaerobic sludge blanket reactor. JECE 2015;3:507-14.

[19] Costa FJCB, Rocha BBM, Viana CE, Toledo AC. Utilization of vinasse effluents from an anaerobic reactor. Water Sci Technol 1986;18(12):135-41.

[20] Craveiro AM, Soares HM, Schmidell W. Technical aspects and cost estimations for anaerobic systems treating vinasse and brewery/soft drink wastewaters. Water Sci Technol 1986;18(12):123-34.

[21] Souza ME, Fuzaro G, Polegato AR. Thermophilic anaerobic digestion of vinasse in pilot plant UASB reactor. Water Sci Technol 1992;25:213-22.

[22] Harada H, Uemura S, Chen AC, Jayadevan J. Anaerobic treatment of a recalcitrant distillery wastewater by a thermophilic UASB reactor. Bioresour Technol 1996;55:215-21.

[23] Wiegant WM, Claassen JA, Lettinga G. Thermophilic anaerobic digestion of high strength wastewaters. Biotechnol Bioeng 1985;27:1374-81.

[24] Syutsubo K, Harada H, Ohashi A. Granulation and sludge retainment during start-up of a thermophilic UASB reactor. Water Sci Technol 1998;38(89):349-57.

[25] Siqueira LM, Damiano ESG, Silva EL. Influence of organic loading rate on the anaerobic treatment of sugarcane vinasse and biogas production in fluidized bed reactor. J Environ Sci Heal A 2013;48(13):1707-16.

[26] Barros VG, Duda RM, Oliveira RA. Biomethane production from vinasse in upflow anaerobic sludge blanket reactors inoculated with granular sludge. Braz J Microbiol 2016. doi: http://dx.doi.org/10.1016/j.bjm.2016.04.021.

[27] Camiloti PR, Mockaitis G, Rodrigues JAD, Damianovic MHRZ, Foresti E, Zaiat M. Innovative anaerobic bioreactor with fixed-structured bed (ABFSB) for simultaneous sulfate reduction and organic matter removal. J Chem Technol Biotechnol 2014;89:1044-50.

[28] Heijnen JJ, Mulder A, Enger W, Hoeks F. Review on the application of anaerobic fluidized bed reactors in waste-water treatment. Chem Eng J 1989;41:B37-50.

[29] Zaiat M, Cabral AKA, Foresti E. Fixed-film horizontal-flow anaerobic reactor for the treatment of wastewaters: conception and preliminary performance assessment. REBEQ 1994;11(2):33-42.

[30] APHA, Awwa, WEF. Standard methods for the examination of water and wastewater. 21st ed. Washingtion D.C: APHA; 2005.

[31] Adorno MAT, Hirasawa JS, Varesche MBA. Development and validation of two methods to quantify volatile acids (C2-C6) by GC/FID: headspace (automatic and manual) and liquid-liquid extraction (LLE). AJAC 2014;5:406-14.

[32] Ripley LE, Boyle WC, Converse JC. Improved alkalimetric monitoring for anaerobic digestion of high-strength wastes. J Water Pollut Control Fed 1986;58:406-11. 
[33] Dubois SM, Gilles KA, Hamilton JK, Rebers PA, Smith F. Colorimetric methods for determination of sugar and related substance. Anal Chem 1956:228:13-21.

[34] Perna V, Castelló E, Wenzel J, Zampol C, Fontes Lima DM, Borzacconi L, et al. Hydrogen production in an upflow anaerobic packed bed reactor used to treat cheese whey. Int J Hydrogen Energy 2013;38:54-62.

[35] Siles JA, García-García I, Martín A, Martín MA. Integrated ozonation and biomethanization treatments of vinasse derived from ethanol manufacturing. J Hazard Mater 2011;188:247-53.

[36] Penteado ED, Lazaro CZ, Sakamoto IK, Zaiat M. Influence of seed sludge and pretreatment method on hydrogen production in packed-bed anaerobic reactors. Int J Hydrogen Energy 2013;38:6137-45.

[37] Ferraz Jr ADN, Etchebehere C, Zait M. High organic loading rate on thermophilic hydrogen production and metagenomic study at an anaerobic packed-bed reactor treating a residual liquid stream of a Brazilian biorefinery. Bioresour Technol 2015;186:81-8.

[38] Angelidaki I, Sanders W. Assessment of the anaerobic biodegradability of macropollutants. Rev Environ Sci Biotechnol 2004;3:117-29.

[39] Lin Y, Lü F, Shao L, He P. Influence of bicarbonate buffer on the methanogenetic pathway during thermophilic anaerobic digestion. Bioresour Technol 2013;137:245-53.

[40] Bories A, Raynal J, Bazile F. Anaerobic digestion of high-strength distillery wastewater (cane molasses vinasse) in a fixed-film reactor. Biol Waste 1988:23:251-67.

[41] Shrihari S, Tare V. Anaerobic-aerobic treatment of distillery wastes. Water Air Soil Pollut 1989;43:95-108.

[42] Kumar GS, Gupta SK, Singh G. Biodegration of distillery spent wash in anaerobic hybrid reactor. Water Res 2007;41:721-30.
[43] Rintala J. High-rate anaerobic treatment of industrial wastewaters. Water Sci Technol 1991;24(1):69-74.

[44] Yu B, Shan A, Zhang D, Lou Z, Yuan H, Huang X, et al. Dosing time of ferric chloride to disinhibit the excessive volatile fatty acids in sludge thermophilic anaerobic digestion system. Bioresour Technol 2015;189:154-61.

[45] Speece RE, Boonyakitsombut S, Kim M, Azbar N, Ursillo P. Overview of anaerobic treatment: thermophilic and propionate implications. Water Environ Res 2006;78:460-73.

[46] Liang GZ, Wang Y, Zhou Y, Liu H, Wu Z. Variables affecting melanoidins removal from molasses wastewater by coagulation/flocculation. Sep Purif Technol 2009;68:382-9.

[47] Peixoto G, Pantoja-Filho JLR, Agnelli JAB, Barboza M, Zaiat M. Hydrogen and methane production, energy recovery, and organic matter removal from effluents in a two-stage fermentative process. Appl Biochem Biotechnol 2012;168:651-71.

[48] CONAB. The thermoelectric generation with the burning of sugarcane bagasse in Brazil: performance analysis for the season 2009-2010. CONAB, Brasília; 2011. Available from: <http://www.conab.gov.br/OlalaCMS/uploads/arquivos/ 11 $05 \quad 05 \quad 15 \quad 45 \quad 40$ geracao termo baixa_res.pdf> [Last access: 2015 May 26, in Portuguese]

[49] CONAB. Monitoring of the Brazilian crop: sugarcane, third survey, December/ 2014. CONAB, Brasília; 2014. Available from: <http://www.conab gov.br OlalaCMS/uploads/arquivos/14_12_19_09_02_49_boletim_cana_portugues_3o_lev_-_2014-15.pdf> [Last access: 2015 May 26, in Portuguese].

[50] Itaipu Binacional, 2014. Sustainability report - 2014. Available from <https:/| www.itaipu.gov.br/sites/default/files/RS-2014-Port-2.pdf> [Last access: 2015 December 11, in Portuguese]. 